\title{
Penampilan Agronomi dan Uji Toleransi Naungan Galur Dihaploid Padi Gogo Hasil Kultur Antera
}

\author{
Agronomic Performance and Shading Tolerance Evaluation of \\ Upland Rice Dihaploid Lines Obtained from Anther Culture
}

\author{
Kartika Kirana Sangga Mara1, Bambang Sapta Purwoko ${ }^{2 *}$, Eko Sulistyono ${ }^{2}$, dan Iswari Saraswati Dewi ${ }^{3}$ \\ ${ }^{1}$ Program Studi Agronomi dan Hortikultura, Sekolah Pascasarjana, Institut Pertanian Bogor \\ ${ }^{2}$ Departemen Agronomi dan Hortikultura, Fakultas Pertanian, Institut Pertanian Bogor \\ (Bogor Agricultural University), Jl. Meranti, Kampus IPB Darmaga, Bogor, 16680, Indonesia \\ ${ }^{3}$ Balai Besar Bioteknologi dan Sumberdaya Genetika Tanaman Pertanian \\ Jl. Tentara Pelajar, No. 3A, Cimanggu, Bogor 16111, Indonesia \\ Diterima 2 April 2014/Disetujui 14 Juli 2014
}

\begin{abstract}
Shifting of upland rice cultivation to marginal land faces drought stress, while planting under young plantation faces shading stress. There should be lines or varieties with good agronomic character and tolerant to the shading stress. Lines used in this experiment were obtained from anther culture, i.e., III3-4-6-1, I5-10-1-1, WI-44, GI-7, O18-b-1, IW-67, IG-19, IG-38, IW-56, B13-2-e. Two experiments were conducted, i.e., agronomic performance experiment and shading tolerance experiment with a quick test method at seedling phase. Batutegi and Way Rarem were used as check varieties in the agronomic experiment. In shading tolerance experiment, Kalimutu was used as sensitive check and Jatiluhur was tolerant check varieties. The results of experiment indicated that B13-2-e (4.64 ton $\left.\mathrm{ha}^{-1}\right)$ and WI-44 line (4.05 ton ha $\mathrm{s}^{-1}$ ) dihaploid lines showed high grain yield and comparable to Way Rarem (4.95 ton ha $\left.{ }^{-1}\right)$. B13-2-e and WI-44 lines were tolerant to shading. Another tolerant lines to shading, i.e., I5-10-1-1, O18-b-1, and IW-56. B13-2-e and WI-44 lines were recommended to advanced verification on multiple cropping system.
\end{abstract}

Keywords: dry land, multiple cropping

\section{ABSTRAK}

Pergeseran budidaya padi gogo ke lahan marjinal menghadapi kondisi kekeringan, sementara penanaman padi gogo di bawah tegakan tanaman perkebunan berumur muda menghadapi cekaman naungan. Oleh karena itu diperlukan galur yang mempunyai penampilan agronomi baik dan toleran terhadap cekaman naungan. Penelitian ini bertujuan menguji penampilan agronomi galur padi gogo dan toleransinya terhadap cekaman naungan. Galur padi gogo yang digunakan dalam percobaan ini adalah galur hasil kultur antera, yaitu III3-4-6-1, I5-10-1-1, WI-44, GI-7, O18-b-1, IW-67, IG-19, IG-38, IW-56, B13-2-e. Ada dua percobaan yang dilakukan yaitu percobaan untuk mengevaluasi penampilan agronomi dan uji cekaman naungan. Batutegi dan Way Rarem digunakan sebagai varietas kontrol dalam percobaan evaluasi penampilan agronomi. Kalimutu digunakan sebagai varietas kontrol peka dan Jatiluhur sebagai varietas kontrol toleran dalam uji cekaman naungan. Hasil

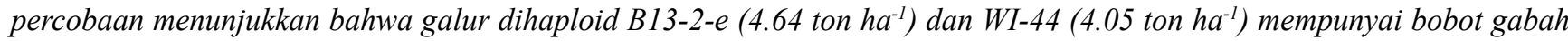
kering giling tinggi dan sebanding dengan varietas pembanding Way Rarem (4.95 ton ha ${ }^{-1}$ ). Galur B13-2-e dan WI-44 termasuk kategori toleran terhadap naungan. Galur toleran lainnya yaitu galur I5-10-1-1, O18-b-1, dan IW-56. Galur B132-e dan WI-44 direkomendasi untuk dapat diverifikasi lanjut pada sistem tumpangsari.

Kata kunci: lahan kering, tumpangsari

\section{PENDAHULUAN}

Padi gogo adalah penghasil beras yang banyak dibudidayakan di Indonesia setelah padi sawah. Produksi

\footnotetext{
* Penulis untuk korespondensi. e-mail: bambangpurwoko@gmail. com
}

padi nasional pada tahun 2013 sebesar 70.87 juta ton gabah kering giling mengalami peningkatan sebanyak 1.81 juta ton $(2.62 \%)$ dibandingkan tahun 2012. Peningkatan produksi padi pada tahun 2013 tersebut diperkirakan terjadi di Jawa sebesar 0.87 juta ton dan di luar Jawa sebesar 0.94 juta ton. Peningkatan produksi diperkirakan terjadi karena peningkatan luas panen seluas 324.39 ribu ha (2.41\%) dan produktivitas sebesar $0.10 \mathrm{ku} \mathrm{ha}^{-1}(0.19 \%)$ (BPS, 2013). 
Namun demikian, ketersediaannya yang kontinu dari tahun ke tahun tidak dapat dipastikan akibat semakin sempitnya lahan subur dan kondisi perubahan iklim saat ini.

Semakin sempitnya lahan subur menyebabkan budidaya padi gogo saat ini bergeser ke lahan marjinal. Lahan marjinal ini berupa lahan kering dengan tingkat kesuburan tanah yang rendah, ketersediaan air yang rendah dan tipe lereng yang curam. Tahun 2005, Indonesia memiliki 148 juta ha lahan kering (78\%) dan 40.20 juta ha lahan basah (22\%). Dari total luas 148 juta ha, lahan kering yang sesuai untuk budi daya pertanian hanya sekitar 76.22 juta ha (52\%), sebagian besar terdapat di dataran rendah (70.71 juta ha atau 93\%) dan sisanya di dataran tinggi. Di wilayah dataran rendah, lahan datar bergelombang (lereng <15\%) yang sesuai untuk pertanian tanaman pangan mencakup 23.26 juta ha. Lahan dengan lereng 15\%-30\% lebih sesuai untuk tanaman tahunan (47.45 juta ha). Di dataran tinggi, lahan yang sesuai untuk tanaman pangan hanya sekitar 2.07 juta ha, dan untuk tanaman tahunan 3.44 juta ha (Abdurachman et al., 2008). Pergeseran ini akibat dari konversi lahan subur terutama di Pulau Jawa yang tidak terkendali dan degradasi lahan sehingga ketersediaan lahan pertanian makin terbatas (Djaenudin, 2008). Hal ini menyebabkan padi gogo sebagai alternatif penghasil beras mempunyai potensi pengembangan yang luas tetapi membutuhkan penanganan serius dalam budidayanya di lahan marjinal.

Menurut Toha (2005) daerah pengembangan padi gogo antara lain daerah datar/bantaran sungai, kawasan perbukitan Daerah Aliran Sungai (DAS) dan sebagai tanaman tumpang sari perkebunan dan hutan tanaman industri muda. Sebagai tanaman tumpang sari, penanaman dilakukan saat tanaman pokok belum menghasilkan atau sampai batas terjadi naungan maksimum, yaitu intensitas cahaya 50\% (Sopandie et al., 2003a; Sasmita et al., 2006 ). Pertanaman padi gogo sebagai tanaman tumpang sari perkebunan karet dapat diusahakan sampai tahun ke tiga dan untuk perkebunan kelapa sawit sampai tahun ke empat. Bila siklus peremajaan tanaman perkebunan karet dan kelapa sawit dilakukan setiap 25 tahun sekali, maka potensi pengusahaan padi gogo sebagai tanaman tumpangsari di kedua jenis perkebunan tersebut dapat mencapai luasan 12\% (Toha, 2005). Kendala utama di lahan tersebut yaitu intensitas cahaya rendah (naungan) di bawah tegakan perkebunan/hutan tanaman industri selain kemasaman tanah yang tinggi (Sopandie dan Trikoesoemaningtyas, 2011; Barus, 2013) dan ancaman kekeringan (Sopandie dan Trikoesoemaningtyas, 2011) sebagai dampak perubahan iklim yang menyebabkan periode musim hujan dan musim kemarau tidak dapat lagi diramalkan secara pasti (Budiastuti, 2009). Kendala lain yaitu serangan organisme pengganggu tanaman (OPT) khususnya penyakit blas (Pyricularia grisea).

Menurut Sopandie et al. (2003a) naungan akan menurunkan aktivitas fotosintesis yang akan mengakibatkan penurunan fotosintat. Tanaman toleran mempunyai tingkat efisiensi penerimaan cahaya yang lebih tinggi pada kondisi normal dan terutama saat ternaungi dibanding tanaman yang peka. Karakter padi gogo toleran naungan mempunyai kemampuan meningkatkan luas area penangkapan cahaya dan meningkatkan tinggi tanaman sehingga fotosintesis relatif optimum (Sasmita et al., 2006). Karakter ini akan mempengaruhi mekanisme fisiologi di dalam jaringan seperti penurunan nisbah klorofil $a / b$ (Lautt et al., 2000).

Salah satu upaya yang efektif untuk mengatasi kendala ini adalah dengan memperbaiki adaptasi tanaman padi gogo terhadap cekaman naungan tersebut dengan teknik pemuliaan dan bioteknologi tanaman. Salah satu teknik yang digunakan untuk mendapatkan galur dengan karakter yang diinginkan dalam waktu yang relatif singkat dan lebih hemat dalam biaya dan tenaga adalah teknik kultur antera (Dewi dan Purwoko, 2012). Penelitian mengenai perakitan varietas baru dengan menggunakan teknik kultur antera tahun 2002-2010 menghasilkan beberapa galur yaitu IW-67, IG-19, IG-38, IW-56, WI-44, GI-7 (Sasmita, 2006). Galur IG-19 dan IW-56 konsisten toleran terhadap naungan alami dan cukup adaptif terhadap kondisi tumpangsari dengan jagung (Sasmita et al., 2006), O18-b-1 dan B13-2-e toleran aluminium (Purwoko et al., 2010), III3-4-6-1 dan I5-10-1-1 toleran aluminium (Herawati et al., 2008). Set galur tersebut telah diuji di delapan lokasi di Indonesia (Sulaeman et al., 2011).

Hasil dari penelitian ini diharapkan akan menambah informasi tentang sifat khusus galur yang akan dilepas sebagai varietas padi gogo. Penelitian ini bertujuan untuk mengetahui penampilan agronomi (komponen hasil dan hasil) galur-galur dihaploid padi gogo serta menguji toleransinya terhadap cekaman naungan.

\section{BAHAN DAN METODE}

\section{Penampilan Agronomi}

Percobaan penampilan agronomi galur padi gogo dihaploid dilakukan di Kebun Percobaan IPB di Cikarawang pada bulan Desember 2011 sampai dengan Maret 2012. Percobaan penampilan agronomi menggunakan benih sepuluh galur padi gogo dihaploid yaitu III3-4-6-1, I510-1-1, WI-44, GI-7, O18-b-1, IW-67, IG-19, IG-38, IW56, B13-2-e (Tabel 1) dan varietas pembanding Batutegi dan Way Rarem. Percobaan ini menggunakan Rancangan Acak Kelompok satu faktor yaitu dua belas genotipe padi gogo dengan empat ulangan sehingga terdapat 48 petak percobaan. Setiap petakan lahan berukuran $4 \mathrm{~m} \mathrm{x} 5 \mathrm{~m}$. Jarak tanam $30 \mathrm{~cm} \times 15 \mathrm{~cm}$. Benih ditanam langsung dengan cara tugal. Jumlah benih 5 butir tiap lubang. Dosis pupuk yang digunakan untuk tiap hektar yaitu $200 \mathrm{~kg}$ Urea, $100 \mathrm{~kg} \mathrm{SP}-$ $36,100 \mathrm{~kg} \mathrm{KCl}$, dan 10 ton pupuk kandang. Pemupukan dilakukan saat tanam, 4 minggu setelah tanam (MST), dan 7 MST. Penyiangan dilakukan pada 4, 7, dan 10 MST. Pengendalian hama dan penyakit tanaman dilakukan secara intensif sesuai kebutuhan.

Pengamatan dilakukan pada karakter agronomi yaitu tinggi tanaman saat panen $(\mathrm{cm})$, jumlah anakan produktif (batang), umur berbunga (hari), umur panen (hari), panjang malai $(\mathrm{cm})$, persentase gabah isi per malai (\%), jumlah gabah total per malai (butir), bobot gabah 1,000 butir (g), bobot gabah kering giling (GKG) (ton ha $\left.{ }^{-1}\right)$. Data dianalisis ragam, apabila berpengaruh nyata maka diuji lanjut dengan Uji Beda Nyata Terkecil (LSD) pada taraf 5\%. 
Tabel 1. Asal persilangan galur-galur padi gogo yang digunakan

\begin{tabular}{llll}
\hline Galur & Asal persilangan & Tujuan & Sumber \\
\hline III3-4-6-1 & Fatmawati/SGJT-36 & Hasil tinggi & Herawati et al., 2008 \\
I5-10-1-1 & SGJT-28/Fatmawati & Toleran Al & Purwoko et al., 2010 \\
O18-b-1 & Krowal/Jatiluhur//ITA-247Way Rarem & Hasil tinggi & \\
B13-2-e & Dupa/Way Rarem//Dodokan/Jatiluhur & Toleran Al & Sasmita, 2006 \\
WI-44 & WI = Way Rarem/ITA-247 & Padi lahan kering & \\
IW-67 & IW = ITA-247/Way Rarem & Toleran naungan & \\
IW-56 & & & \\
GI-7 & GI = Gajah Mungkur/ITA-247 & & \\
IG-19 & IG = ITA-247/Gajah Mungkur & & \\
IG-38 & & & \\
\hline
\end{tabular}

\section{Toleransi Naungan}

Percobaan toleransi naungan dilakukan sejak pertengahan bulan Desember 2012 sampai dengan Februari 2013 di rumah kaca Balai Besar Penelitian dan Pengembangan Bioteknologi dan Sumberdaya Genetik Pertanian Cimanggu, Bogor. Percobaan toleransi naungan menggunakan metode uji cepat fase bibit dan penilaian toleransi (berdasarkan persentase tanaman hidup dan skor kerusakan bibit) menurut Sasmita (2006). Genotipe yang digunakan ialah dua belas genotipe yang sama pada percobaan penampilan agronomi ditambah varietas pembanding peka naungan Kalimutu dan pembanding toleran naungan Jatiluhur. Rancangan yang digunakan adalah Rancangan Acak Kelompok empat ulangan. Setiap satuan percobaan terdiri atas sepuluh tanaman. Benih dikecambahkan 3 hari kemudian bibit ditanam dalam bak plastik dan dipelihara selama 10 hari dengan cahaya penuh. Tiap bak terdiri atas 14 genotipe. Tiap satuan percobaan terdiri atas 10 tanaman. Bibit kemudian dipelihara selama 14 hari di ruang gelap.

Pengamatan dilakukan tiap dua hari sejak hari ketiga di ruang gelap terhadap persentase tanaman hidup dan skor kerusakan bibit. Nilai skor kerusakan: $1=0-10 \%$ bagian daun mengering, $3=>10 \%-30 \%$ bagian daun mengering, 5 $=>30 \%-50 \%$ bagian daun mengering, $7=50 \%-70 \%$ bagian daun mengering, dan $9=>70 \%$ bagian daun mengering. Skor $\leq 3$ menunjukkan vigor bibit baik dengan daun relatif segar. Skor $\geq 5$ menunjukkan vigor bibit kurang baik/tidak hidup. Skor kerusakan bibit varietas peka naungan mencapai skor 5 (tidak hidup) pada tujuh hari gelap. Hasil pengamatan persentase tanaman hidup pada hari ke tujuh dianalisis ragam dan apabila berpengaruh nyata akan diuji lanjut dengan Uji Beda Nyata Terkecil (LSD) pada taraf 5\%.

\section{HASIL DAN PEMBAHASAN}

\section{Penampilan Agronomi}

Hasil analisis ragam $(\alpha 5 \%)$ dan uji lanjut Beda Nyata Terkecil (LSD) ( $\alpha$ 5\%) menunjukkan seluruh karakter agronomi galur-galur hasil kultur antera berbeda nyata dibandingkan dengan varietas pembanding (Batutegi dan Way Rarem) kecuali pada bobot GKG. Tabel 2 menunjukkan tanaman tertinggi yaitu pada galur III3-4-6-1 $(139.45 \mathrm{~cm})$ kemudian diikuti varietas Way Rarem $(135.95 \mathrm{~cm})$ dan galur I5-10-1-1 (132.05 cm). Tanaman tipe pendek dimiliki galur O18-b-1 $(85.65 \mathrm{~cm})$, IW-67 $(91.95 \mathrm{~cm})$, dan IW-56 $(90.20 \mathrm{~cm})$. Jumlah anakan produktif terbanyak dimiliki galur IW-67 (21.0 batang) yang tidak berbeda nyata dengan galur IW-56 (20.3 batang). Jumlah anakan produktif terbanyak dimiliki galur IW-67 (21.0 batang) dan IW-56 (20.3 batang). Jumlah anakan paling sedikit dimiliki galur III3-4-6-1 (9.2 batang). Galur O18-b-1 mempunyai umur panen paling singkat dibanding galur lainnya (91.5 hari). Varietas Batutegi mempunyai umur panen yang paling lama (112.0 hari).

Tabel 3 menunjukkan galur III3-4-6-1 memiliki malai terpanjang $(28.82 \mathrm{~cm})$, dan galur O18-b-1 $(22.53 \mathrm{~cm})$ adalah malai terpendek. Persentase gabah isi terbanyak dimiliki oleh galur IG-38 (92.3\%) dan paling sedikit dimiliki varietas Batutegi (77.3\%). Galur III3-4-6-1 dan I5-10-11 mempunyai jumlah gabah total per malai tidak berbeda nyata dengan varietas Way Rarem. Jumlah gabah total per malai terbanyak dimiliki varietas Batutegi (312.6 butir) dan paling sedikit dimiliki galur IW-67 (100.2 butir).

Tabel 4 menunjukkan bobot 1,000 butir tertinggi dihasilkan oleh galur IG-38 (38.99 g), IG-19 (38.11 g), dan GI-7 (38.07 g), sedangkan terendah dihasilkan oleh I510-1-1 (23.45 g). Bobot gabah kering giling (GKG) yang dihasilkan galur-galur hasil kultur antera masih berada di bawah varietas Way Rarem (4.95 ton ha ${ }^{-1}$ ). Galur dengan bobot GKG yang tidak berbeda nyata dengan varietas Way Rarem yaitu galur B13-2-e (4.64 ton ha $\mathrm{h}^{-1}$ ) dan galur WI44 (4.05 ton $\mathrm{ha}^{-1}$ ). Bobot GKG galur hasil kultur antera terendah dihasilkan oleh galur III3-4-6-1 (2.49 ton ha ha $^{-1}$.

Galur hasil kultur antera B13-2-e dengan bobot GKG 4.64 ton $\mathrm{ha}^{-1}$ mempunyai anakan produktif banyak (16.4 batang), persentase gabah isi sedang (87.0\%) dan bobot 1,000 butir $25.46 \mathrm{~g}$ walaupun karakter gabahnya mudah rontok. Galur WI-44 dengan bobot GKG 4.05 ton ha- ${ }^{-1}$ mempunyai jumlah anakan produktif 15.5 batang, persentase gabah isi tinggi (91.8\%) dan bobot 1,000 butir $27.78 \mathrm{~g}$, 
Tabel 2. Tinggi tanaman, jumlah anakan produktif dan umur panen galur dihaploid padi gogo hasil tanam di lapangan

\begin{tabular}{|c|c|c|c|}
\hline Galur & $\begin{array}{l}\text { Tinggi tanaman } \\
(\mathrm{cm})\end{array}$ & $\begin{array}{c}\text { Jumlah anakan produktif } \\
\text { (batang) }\end{array}$ & $\begin{array}{c}\text { Umur panen } \\
\text { (hari) }\end{array}$ \\
\hline III3-4-6-1 & $139.45 a$ & $9.2 \mathrm{~d}$ & $106.3 \mathrm{~cd}$ \\
\hline I5-10-1-1 & $132.05 \mathrm{abc}$ & $15.9 b$ & $106.5 b c$ \\
\hline WI-44 & $106.85 \mathrm{~d}$ & $15.5 b$ & $105.5 \mathrm{e}$ \\
\hline GI-7 & $130.00 \mathrm{bc}$ & $12.0 \mathrm{c}$ & $96.5 f$ \\
\hline O18-b-1 & $85.65 \mathrm{e}$ & $11.2 \mathrm{~cd}$ & $91.5 \mathrm{~g}$ \\
\hline IW-67 & $91.95 \mathrm{e}$ & $21.0 \mathrm{a}$ & $105.8 \mathrm{de}$ \\
\hline IG-19 & $129.38 b c$ & $10.7 \mathrm{~cd}$ & $96.5 f$ \\
\hline IG-38 & $129.35 b c$ & $10.9 \mathrm{~cd}$ & $97.0 \mathrm{f}$ \\
\hline IW-56 & $90.20 \mathrm{e}$ & $20.3 a$ & $107.0 \mathrm{~b}$ \\
\hline B13-2-e & $127.40 \mathrm{c}$ & $16.4 \mathrm{~b}$ & $105.8 \mathrm{de}$ \\
\hline Batutegi & $128.80 \mathrm{bc}$ & $9.8 \mathrm{~cd}$ & $112.0 \mathrm{a}$ \\
\hline Way Rarem & $135.95 \mathrm{ab}$ & $10.7 \mathrm{~cd}$ & 106.0cde \\
\hline
\end{tabular}

Keterangan: Angka yang diikuti huruf yang sama pada kolom yang sama menunjukkan hasil yang tidak berbeda nyata berdasarkan Uji BNT (LSD) pada taraf $\alpha 5 \%$

Tabel 3. Panjang malai, persentase gabah isi dan jumlah gabah total per malai galur dihaploid padi gogo hasil tanam di lapangan

\begin{tabular}{lccc}
\hline Galur & $\begin{array}{c}\text { Panjang malai } \\
(\mathrm{cm})\end{array}$ & $\begin{array}{c}\text { Persentase gabah isi } \\
(\%)\end{array}$ & $\begin{array}{c}\text { Jumlah gabah total per malai } \\
(\mathrm{butir})\end{array}$ \\
\hline III3-4-6-1 & $28.81 \mathrm{a}$ & $85.5 \mathrm{bcd}$ & $180.4 \mathrm{bc}$ \\
I5-10-1-1 & $27.07 \mathrm{~b}$ & $89.8 \mathrm{abc}$ & $173.2 \mathrm{bcd}$ \\
WI-44 & $24.58 \mathrm{~cd}$ & $91.8 \mathrm{ab}$ & $122.7 \mathrm{efg}$ \\
GI-7 & $24.44 \mathrm{cde}$ & $85.5 \mathrm{bcd}$ & $130.7 \mathrm{ef}$ \\
O18-b-1 & $22.53 \mathrm{f}$ & $86.4 \mathrm{abcd}$ & $162.9 \mathrm{~cd}$ \\
IW-67 & $23.88 \mathrm{cde}$ & $91.0 \mathrm{ab}$ & $100.2 \mathrm{~g}$ \\
IG-19 & $23.39 \mathrm{def}$ & $82.4 \mathrm{de}$ & $134.5 \mathrm{e}$ \\
IG-38 & $24.02 \mathrm{cde}$ & $92.3 \mathrm{a}$ & $128.8 \mathrm{ef}$ \\
IW-56 & $23.33 \mathrm{ef}$ & $83.5 \mathrm{cde}$ & $104.4 \mathrm{fg}$ \\
B13-2-e & $24.70 \mathrm{c}$ & $87.0 \mathrm{abcd}$ & $147.4 \mathrm{de}$ \\
Batutegi & $26.16 \mathrm{~b}$ & $77.3 \mathrm{e}$ & $312.6 \mathrm{a}$ \\
Way Rarem & $23.32 \mathrm{ef}$ & $89.3 \mathrm{abc}$ & $198.6 \mathrm{~b}$ \\
\hline
\end{tabular}

Keterangan: Angka yang diikuti huruf yang sama pada kolom yang sama menunjukkan hasil yang tidak berbeda nyata berdasarkan Uji BNT (LSD) pada taraf $\alpha 5 \%$

tetapi karakter gabahnya tidak mudah rontok. Peneliti sebelumnya melaporkan galur WI-44 (4.72 ton ha' $\mathrm{h}^{-1}$ ) yang mempunyai rata-rata hasil GKG melebihi varietas Batutegi (4.38 ton $\mathrm{ha}^{-1}$ ) dan varietas Way Rarem (4.62 ton ha ${ }^{-1}$ ) dalam pengujian di delapan lokasi (Sulaeman et al., 2011). Galur III3-4-6-1 dengan bobot GKG terendah (2.49 ton $\left.\mathrm{ha}^{-1}\right)$ mempunyai jumlah anakan produktif paling rendah (9.2 batang), walaupun malainya panjang $(28.82 \mathrm{~cm})$ dan bobot 1,000 butir $29.68 \mathrm{~g}$. Galur O18-b-1 yang mempunyai umur panen yang singkat atau genjah, mempunyai bobot GKG agak rendah (2.91 ton $\left.\mathrm{ha}^{-1}\right)$.

\section{Uji Toleransi Naungan}

Persentase Tanaman Hidup. Galur GI-7, IG-19, IG38, varietas Batutegi dan Kalimutu mempunyai persentase tanaman hidup di bawah $40 \%$ yang dikategorikan peka (Tabel 5). Persentase tanaman hidup paling tinggi ditunjukkan oleh galur B13-2-e (95\%), yang tidak berbeda nyata dengan galur I5-10-1-1 (92.5\%) dan WI-44 (92.5\%). Persentase tanaman hidup paling rendah dimiliki oleh galur IG-19, IG-38 dan varietas Batutegi (masing-masing 0\%). 
Tabel 4. Bobot 1,000 butir dan bobot gabah kering giling galur dihaploid padi gogo hasil tanam di lapangan

\begin{tabular}{lccc}
\hline Galur & $\begin{array}{c}\text { Bobot 1,000 butir } \\
(\mathrm{g})\end{array}$ & $\begin{array}{c}\text { Bobot gabah per plot } \\
(\text { kg per petak })\end{array}$ & $\begin{array}{c}\text { Bobot gabah kering giling } \\
(\text { ton ha-1 }\end{array}$ \\
\hline III3-4-6-1 & $29.68 \mathrm{~b}$ & 2.92 & $2.49 \mathrm{~d}$ \\
I5-10-1-1 & $23.45 \mathrm{~h}$ & 4.32 & $3.71 \mathrm{bc}$ \\
WI-44 & $27.78 \mathrm{bcd}$ & 4.67 & $4.05 \mathrm{abc}$ \\
GI-7 & $38.07 \mathrm{a}$ & 4.12 & $3.56 \mathrm{bcd}$ \\
O18-b-1 & $28.22 \mathrm{bc}$ & 3.29 & $2.91 \mathrm{~cd}$ \\
IW-67 & $27.08 \mathrm{cde}$ & 4.25 & $3.66 \mathrm{bc}$ \\
IG-19 & $38.11 \mathrm{a}$ & 4.03 & $3.48 \mathrm{~cd}$ \\
IG-38 & $38.88 \mathrm{a}$ & 4.14 & $3.72 \mathrm{bc}$ \\
IW-56 & $24.30 \mathrm{fgh}$ & 3.55 & $3.16 \mathrm{~cd}$ \\
B13-2-e & $25.46 \mathrm{efg}$ & 5.27 & $4.64 \mathrm{ab}$ \\
Batutegi & $23.96 \mathrm{gh}$ & 4.18 & $3.59 \mathrm{bcd}$ \\
Way Rarem & $26.06 \mathrm{def}$ & 5.65 & $4.95 \mathrm{a}$ \\
\hline
\end{tabular}

Keterangan: Angka yang diikuti huruf yang sama pada kolom bobot 1,000 butir menunjukkan hasil yang tidak berbeda nyata berdasarkan Uji BNT (LSD) pada taraf $\alpha$ 5\%. Angka yang diikuti huruf yang sama pada kolom bobot gabah kering giling menunjukkan hasil yang tidak berbeda nyata berdasarkan Uji BNT (LSD) pada taraf $\alpha 10 \%$

Skor Kerusakan Bibit. Kemampuan tanaman bertahan hidup juga dapat dilihat dari skor kerusakan bibit di ruang gelap selama 7 hari (Tabel 5). Pengamatan pada umur 7 hari gelap, galur GI-7, IG-19, IG-38, varietas Batutegi dan Kalimutu (varietas pembanding peka naungan) mencapai skor 4.9-5.5 dan skor varietas Batutegi adalah yang tertinggi. Galur III3-4-6-1, I5-10-1-1, WI-44, O18-b-1, IW-67, IW-
56, B13-2-e, varietas Way Rarem dan Jatiluhur (varietas pembanding toleran naungan) mempunyai skor 2.8-4.2. Skor galur III3-4-6-1 dan IW-67 berada di atas varietas Jatiluhur.

Uji cepat ruang gelap memiliki kesesuaian yang tinggi (93.3\%) dengan hasil percobaan pada naungan buatan paranet 50\% dan memiliki kesesuaian sedang (56\%)

Tabel 5. Hasil uji cepat toleransi galur dihaploid padi gogo terhadap naungan pada fase bibit

\begin{tabular}{|c|c|c|c|}
\hline \multirow{2}{*}{ Galur } & \multicolumn{2}{|c|}{7 hari gelap } & \multirow{2}{*}{ Kategori } \\
\hline & Persentase tanaman hidup & Skor kerusakan bibit & \\
\hline III3-4-6-1 & $50.0 \mathrm{c}$ & 4.0 & Moderat \\
\hline I5-10-1-1 & $92.5 \mathrm{ab}$ & 3.0 & Toleran \\
\hline WI-44 & $92.5 \mathrm{ab}$ & 3.2 & Toleran \\
\hline GI-7 & $2.5 \mathrm{~d}$ & 5.3 & Peka \\
\hline O18-b-1 & $70.0 \mathrm{bc}$ & 3.6 & Toleran \\
\hline IW-67 & $55.0 \mathrm{c}$ & 3.9 & Moderat \\
\hline IG-19 & $0.0 \mathrm{~d}$ & 5.1 & Peka \\
\hline IG-38 & $0.0 \mathrm{~d}$ & 5.2 & Peka \\
\hline IW-56 & $67.5 \mathrm{c}$ & 3.6 & Toleran \\
\hline B13-2-e & $95.0 \mathrm{a}$ & 2.8 & Toleran \\
\hline Batutegi & $0.0 \mathrm{~d}$ & 5.5 & Peka \\
\hline Way Rarem & $50.0 \mathrm{c}$ & 4.2 & Moderat \\
\hline Kalimutu & $2.5 \mathrm{~d}$ & 4.9 & Peka \\
\hline Jatiluhur & $65.0 \mathrm{c}$ & 3.7 & Toleran \\
\hline
\end{tabular}

Keterangan: Angka yang diikuti huruf yang sama pada kolom yang sama menunjukkan hasil yang tidak berbeda nyata berdasarkan Uji BNT/LSD pada taraf $\alpha 5 \%$. Tanaman hidup $\geq 60 \%$ dengan skor kerusakan bibit $<5$ toleran, $=7$ moderat, $>7$ peka. Tanaman hidup 40\%-60\% dengan skor kerusakan bibit $<5$ moderat, $\geq 5$ peka. Tanaman hidup $<40 \%$ dengan skor kerusakan bibit 1-9 peka (Sasmita, 2006) 
dengan hasil uji lapangan di bawah tegakan karet (Sopandie et al., 2003b). Naungan menurunkan aktivitas fotosintesis yang akan menurunkan hasil fotosintat (Sopandie et al., 2003a; Santosa et al., 2000). Hal ini terjadi pada kedelai di lingkungan ternaungi, yang mengalami penurunan bobot biji lebih dari 50\% (Susanto dan Sundari, 2011) dan pada padi gogo yang ditumpangsarikan dengan jagung manis dengan jarak $50 \mathrm{~cm}$ x $30 \mathrm{~cm}$ menghasilkan bobot 1,000 butir paling rendah dibandingkan dengan jarak tanam yang lebih lebar (Dewi et al., 2014).

Skor kerusakan bibit pada galur toleran naungan (I510-1-1, WI-44, O18-b-1, IW-56, B13-2-e) yang rendah menunjukkan warna daun dengan intensitas kehijauan yang tinggi. Semakin hijau suatu helaian daun kedelai kandungan klorofilnya akan semakin tinggi. Peningkatan intensitas kehijauan dalam cahaya rendah merupakan gambaran adanya akumulasi klorofil pada permukaan daun bagian atas (Muhuria et al., 2006). Kondisi ternaungi menyebabkan genotipe atau tanaman peka dan toleran samasama mengalami peningkatan klorofil (klorofil $a$, klorofil $b$ dan total klorofil) sehingga mengalami penurunan nisbah klorofil $a / b$ pada padi gogo (Sopandie et al., 2003a), talas (Djukri dan Purwoko, 2003) dan kedelai (Muhuria et al., 2006; Kisman et al., 2007). Nisbah klorofil $a / b$ menurun oleh perlakuan naungan yang berarti bahwa terjadi peningkatan kandungan klorofil $b$ (Sopandie et al., 2003a; Muhuria et al., 2006; Kisman et al., 2007). Penurunan ini pada genotipe atau tanaman toleran lebih rendah dibandingkan yang peka (Sopandie et al., 2003a; Muhuria et al., 2006; Kisman et al., 2007).

Skor kerusakan bibit pada galur peka naungan yang tinggi menunjukkan warna daun dengan intensitas kehijauan yang rendah dan tajuk tanaman yang tidak kokoh. Hal ini diduga bahwa tajuk tanaman pada galur peka mengalami penurunan fotosintat (karbohidrat). Naungan 50\% paranet menyebabkan galur padi gogo toleran memiliki kandungan pati pada daun dan batang yang lebih tinggi dibandingkan galur peka pada fase vegetatif aktif (Lautt et al., 2000). Varietas-varietas kedelai yang cenderung mengandung karbohidrat yang lebih besar diduga mempunyai kemampuan bertahan hidup pada fase bibit di ruang gelap yang dipengaruhi oleh kandungan pati dan karbohidrat pada daun (kandungan karbohidrat yang relatif tinggi memiliki respirasi yang lebih rendah) (Soverda, 2012).

Berdasarkan Tabel 4, didapat galur dengan bobot GKG tertinggi adalah varietas Way Rarem (4.95 ton ha' $\mathrm{ha}^{-1}$ yang tidak berbeda nyata dengan galur B13-2-e (4.64 ton $\mathrm{ha}^{-1}$ ) dan WI-44 (4.05 ton ha $\mathrm{h}^{-1}$ ) dan bobot GKG terendah adalah galur III3-4-6-1 (2.49 ton ha- ${ }^{-1}$ ). Tabel 5 menunjukkan galur dengan adaptasi toleran terhadap naungan yaitu galur I5-10-1-1, WI-44, O18-b-1, IW-56 dan B13-2-e. Dengan demikian galur I5-10-1-1, WI-44 dan B13-2-e mempunyai potensi hasil tinggi dan toleran naungan sehingga dapat digunakan sebagai tanaman sela di lahan yang ternaungi. Sulaeman et al. (2011) melaporkan galur I5-10-1-1 diikuti WI-44 mempunyai hasil paling stabil di 8 lokasi penelitian. Galur WI-44 (3.24 ton ha ${ }^{-1}$ ) juga memiliki produktivitas tinggi di lingkungan Indramayu yang ternaungi (dikelilingi tegakan pohon jati muda). Galur O18-b-1 dapat ditanam di lahan ternaungi walaupun hasilnya rendah, namun umurnya yang singkat/genjah berpotensi lebih disukai petani.

\section{KESIMPULAN}

Galur B13-2-e (4.64 ton ha' ${ }^{-1}$ ) dan WI-44 (4.05 ton ha' ${ }^{-1}$ ) mempunyai bobot gabah kering giling tinggi dan sebanding dengan varietas pembanding Way Rarem (4.95 ton $\mathrm{ha}^{-1}$ ). Galur B13-2-e $(127.40 \mathrm{~cm})$ memiliki tinggi tanaman sebanding dengan varietas Batutegi $(128.80 \mathrm{~cm})$, sebaliknya galur WI-44 $(106.85 \mathrm{~cm})$ memiliki tinggi tanaman lebih pendek dibanding kedua varietas pembanding. Kedua galur memiliki jumlah anakan produktif relatif sama (15-16 batang) dan lebih banyak dibanding dengan kedua varietas pembanding (9-10 batang). Galur B13-2-e dan WI-44 termasuk kategori toleran terhadap naungan. Galur toleran lainnya yaitu galur I5-10-1-1, O18-b-1, dan IW-56. Galur B13-2-e dan WI-44 direkomendasi untuk dapat diverifikasi lanjut, konsistensi hasil dan toleransinya pada kondisi naungan alami, antara lain pada sistem tumpangsari.

\section{UCAPAN TERIMA KASIH}

Penulis mengucapkan terima kasih kepada Proyek IMHERE IPB atas pendanaan penelitian ini.

\section{DAFTAR PUSTAKA}

Abdurachman, A., A. Dariah, A. Mulyani. 2008. Strategi dan teknologi pengelolaan lahan kering mendukung pengadaan pangan nasional. J. Litbang Pertanian 27:43-49.

Barus, J. 2013. Pemanfaatan lahan di bawah tegakan kelapa di Lampung. J. Lahan Suboptimal 2:68-74.

Budiastuti, S. 2009. Dampak penyimpangan iklim global terhadap hasil pertanian. J. Agrosains 11:22-27.

[BPS] Badan Pusat Statistik. 2013. Berita Resmi Statistik Badan Pusat Statistik no. 73/11/Th XVI. http://www. bps.com [4 Desember 2013].

Dewi, I.S., B.S. Purwoko. 2012. Kultur antera untuk percepatan perakitan varietas padi di Indonesia. J. Agrobiogen 8:78-88.

Dewi, S.S., R. Soelistyono, A. Suryanto. 2014. Kajian pola tanam tumpangsari padi gogo (Oryza sativa L.) dengan jagung manis (Zea mays saccharata sturt L.). J. Produksi Tanaman 2:137-144.

Djaenudin, D. 2008. Perkembangan penelitian sumber daya lahan dan kontribusinya untuk mengatasi kebutuhan lahan pertanian di Indonesia. J. Litbang Pertanian 27:137-145. 
Djukri, B.S. Purwoko. 2003. Pengaruh naungan paranet terhadap sifat toleransi tanaman talas (Colocasia esculenta (L.) Schott). J. Ilmu Pertanian 10:17-25.

Herawati, R., B.S. Purwoko, N. Khumaida, I.S. Dewi. B. Abdullah. 2008. Pembentukan galur haploid ganda padi gogo dengan sifat-sifat tipe baru melalui kultur antera. Bul. Agron. 36:181-187.

Kisman, N. Khumaida, Trikoesoemaningtyas, Sobir, D. Sopandie. 2007. Karakter morfo-fisiologi daun, penciri adaptasi kedelai terhadap intensitas cahaya rendah. Bul. Agron. 35:96-102.

Lautt, B.S., M.A. Chozin, D. Sopandie, L.K. Darusman. 2000. Perimbangan pati-sukrosa dan aktivitas enzim sukrosa fosfat sintase pada padi gogo yang toleran dan peka terhadap naungan. Hayati J. Biosci. 7:3134.

Muhuria, L., K.N. Tyas, N. Khumaida, Trikoesoemaningtyas, D. Sopandie. 2006. Adaptasi kedelai terhadap intensitas cahaya rendah: karakter daun untuk efisiensi penangkapan cahaya. Bul. Agron. 34:133140.

Purwoko, B.S., I.S. Dewi, N. Khumaida. 2010. Rice anther culture to obtain doubled haploids with multiple tolerances. Asia-Pasific J. Mol. Biol. Biotechnol. 18:55-57.

Santosa, E., D. Sopandie, M.A. Chozin, S. Harran. 2000. Adaptasi fisiologi tanaman padi gogo terhadap naungan: konduktansi stomata, laju pertukaran karbon dan respirasi. Comm. Ag. 6:1-8.

Sasmita, P. 2006. Karakterisasi dan evaluasi toleransi padi gogo haploid ganda hasil kultur antera terhadap naungan. Disertasi. Program Pascasarjana, Institut Pertanian Bogor. Bogor.
Sasmita, P., B.S. Purwoko, S. Sujiprihati, I. Hanarida, I.S. Dewi, M.A Chozin. 2006. Evaluasi pertumbuhan dan produksi padi gogo haploid ganda toleran naungan dalam sistem tumpang sari. Bul. Agron. 34:79-86.

Susanto, G.W.A., T. Sundari. 2011. Perubahan karakter agronomi aksesi plasma nutfah kedelai di lingkungan ternaungi. J. Agron. Indonesia 39:1-6.

Sopandie, D., M.A. Chozin, S. Sastrosumarjo, T. Juhaeti, Sahardi. 2003a. Toleransi padi gogo terhadap naungan. Hayati 10:71-75.

Sopandie, D., M.A. Chozin, S. Tjitrosemito, Sahardi. 2003b. Keefektifan uji cepat ruang gelap untuk seleksi ketenggangan terhadap naungan pada padi gogo. Hayati 10:91-95.

Sopandie, D., Trikoesoemaningtyas. 2011. Pengembangan tanaman sela di bawah tegakan tanaman tahunan. Iptek Tanaman Pangan 6:168-182.

Soverda, N. 2012. Uji adaptasi dan toleransi beberapa varietas tanaman kedelai pada naungan buatan. J. Online Univ. Jambi Bioplantae 1:1-13.

Sulaeman, D.D., B.S. Purwoko, I.S. Dewi, M. Syukur, D. Wirnas, H. Safitri. 2011. Yield stability evaluation of upland rice lines obtained from anther culture. $p$. 80-84. In Proceeding of the 7th Asian Crop Science Association Conference. Bogor 27-30 September 2011.

Toha, H.M. 2005. Informasi Padi Gogo dan Pola Pengembangannya. Balai Penelitian Tanaman Padi. Balai Penelitian Tanaman Padi, Badan Penelitian dan Pengembangan Pertanian, Departemen Pertanian. Subang, Indonesia. 